\title{
The Challenges of Designing a Wooden Beam of Composed Section
}

\author{
Alexandre de Macêdo Wahrhaftig and Ricardo Fernandes Carvalho \\ Department of Construction and Structures, Polytechnic School, Federal University of Bahia, Salvador 40210-910, Brazil
}

\begin{abstract}
This work describes details about the challenges and solutions encountered in the timber structure beam. The choice for wood is due to the fact that it is a better material suited for environments with high salinity and, in this context, to reduce maintenance costs. The entire roof was supported only by four columns, which forced the side and frontal beams to exceed spans over 18 meters without intermediate supports. This was the most important challenge of the project: to find a section to the beam which can attend the ultimate limit state and serviceability in wood to the dimensions in project. The answer was clear: It would need to have composed section. A computational model was constructed using the finite element method in order to obtain the efforts on the structural elements. It is important to emphasize that the design of a wood structure requires not only knowledge, but creativity as well, to overcome the challenges posed by the distinctive needs to the detailing of this material. In addition to that, it requires special attention during the construction execution, because of the difficulty that the carpenters have to read the specific plans.
\end{abstract}

Key words: Composed section, wooden structures, design, finite element method, conditions of execution.

\section{Introduction}

The City of Salvador is located in northeastern Brazil and it is one of the main entry points of the country. The city was once established as the first capital of Brazil by the Portuguese, when they arrived at the new land on April 22, 1500. Salvador is deep-rooted into the extensive coast of Brazil which is bathed by Atlantic Ocean. It is roughly at sea level, with a maximum elevation of eight meters and has one of the highest degrees of salinity in Brazil. It presents the $12^{\circ} 58^{\prime} 16^{\prime \prime} \mathrm{S}, 38^{\circ} 30^{\prime} 39^{\prime \prime} \mathrm{W}$ coordinates. Fig. 1 provides a view of the geographical location of Salvador, and the position of the structure studied in relation to the city. Salvador has mainly tropical rainforest climate with no discernible dry season. Temperatures are relatively constant throughout the year, with hot and humid climate conditions. The driest month is January, which gets only about an average of $110 \mathrm{~mm}$ of rain. The rainiest season is between the months of May and July, when it has

Corresponding author: Alexandre de Macêdo Wahrhaftig, D.Sc., research field: engineering. been recorded an average of as much as $789 \mathrm{~mm}$ of rain. The extreme temperatures can be as low as $17^{\circ} \mathrm{C}$ during the winter, and from $23{ }^{\circ} \mathrm{C}$ to $32{ }^{\circ} \mathrm{C}$ during the summer.

Due to climate circumstances and the proximity to the ocean, the city's environment creates a very unfavorable atmosphere to any kind of metallic components in all functions as they are subject to the development of oxidation processes. Furthermore, the air blowing from the ocean makes the oxidation process even more corrosive because the oxidation is enhanced by the wind currents carrying the droplets of water and salt spray. Therefore, the structures require special maintenance condition, aiming not only to prolong the life of the building, but also to ensure structural safety. Wooden structures are indeed an attractive option for such environments, since the inspection and maintenance conditions are not only easier to be carried out, but also less costly as well, because they are restricted to the components connection ensuring that the main structural elements are no longer susceptible to corrosion. 


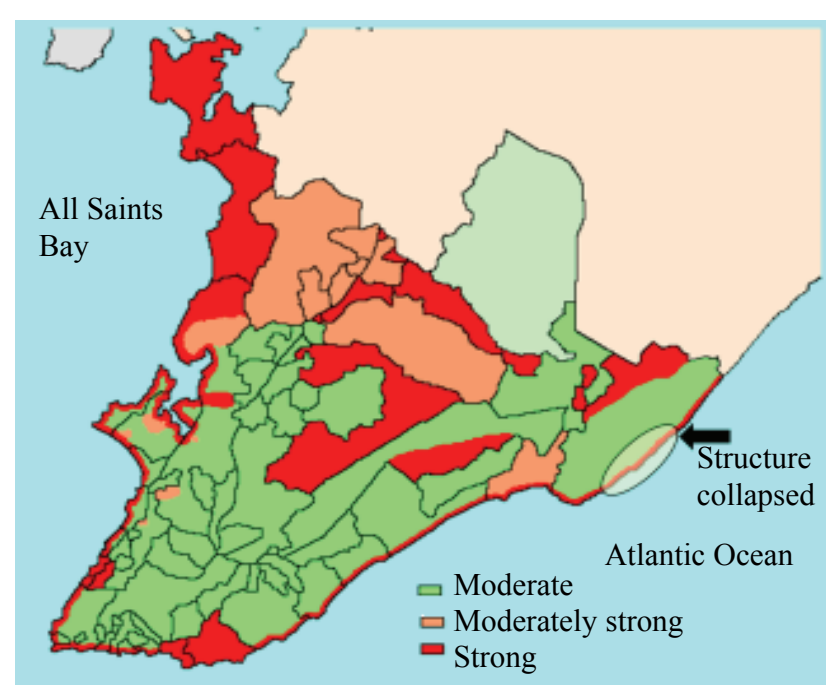

Fig. 1 Geographical position of Salvador and of the position of the structure (adapted from Vilasboas) [1].

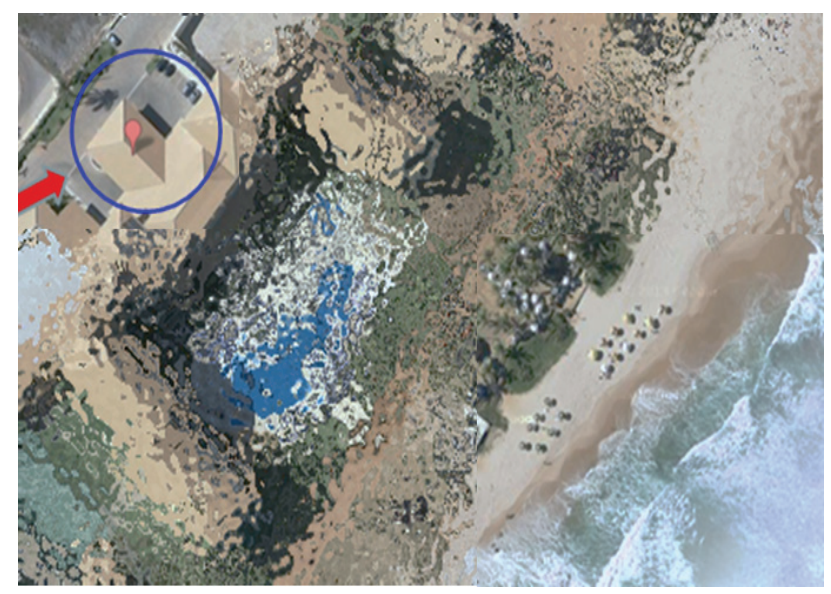

Fig. 2 Satellite location of structure.

As a further study, Portella et al. [1] expended a revision classifying the environmental aggressiveness for reinforced concrete structures in Salvador, where it can be apparent that the collapsed structure is located in an area characterized as strong aggression. In their work, Portella et al. [1] presented environmental corrosion rates at different parts of the metropolitan area of Salvador, including the position of the structure and object of the present examination, which has a high environmental factor rate of 3,231-mg $\mathrm{Cl} / \mathrm{m}^{2} /$ day, situated in a zone regarded as producing corrosion to all exposed ferrous metals.

For this reason, Bijen [2] affirms that civil engineering failures not only exemplify important cost considerations, but they also carry an environmental burden as well. Structures often deteriorate because the required attention is not always present during the design stage, and most standards for structural design do not cover a lifecycle plan. Designing for durability is often left to the structural designer who may not have the required skills, and the result is all too often failure, incurring high maintenance and repair costs. This engineering project aims to ensure durable resilience to the buildings structures for their whole lifecycle, with effective maintenance and subsequent repair techniques involving all personnel in the project, along with deterioration mechanisms and effective measures to reduce the probabilities for failures.

Hansson [3] prepared a study where he looked at over 127 failures cases and their modes of timber structures collapse, and concluded that the most common cause for failure $(41.5 \%)$, is related to weakness in the project definition or mistakes on the strength of the design, followed by poor principles during assembly (14.1\%), on-site alterations (12.5\%), and insufficient data regarding the various environmental facets (11.4\%). In total, about half of the failures are caused by the designer, and about one fourth of them are caused by personnel at the building site. Wood quality, production methods, and production principles are responsible only for a small part (just about 11\%) of the failures.

\section{Problem}

This paper describes exclusively the structure design for wooden beams used to replace the collapsed beam of steel, noting that all other elements have been calculated and designed. As described above, the collapsed structure was situated in environmental conditions of high level of aggressiveness. The structure was constructed in the front part of the building, with a distance of approximately 100 meters from the ocean, as can be seen in Fig. 2.

The ceramic roof tile had a total area of about of $300 \mathrm{~m}^{2}$ and was supported by a steel frame, with the 
exception of the pillars which were made of reinforced concrete. Those pillars were coated by an architectural finishing resembling bricks.

The original steel structure collapsed after seven years, destroying completely the superstructure of the roof, along with the support columns of reinforced concrete situated in the front part of the building. The remaining metallic structure was also replaced taking in consideration the maintenance high costs. The manufacturers hired to rebuild the roof chose to use a wooden structure, considering the fact that the wood material is easy to handle, as it depends on relatively simple technology mastered and available in the country, in addition to the use of low complexity machinery which is technically adequate and economically competitive for all engineering work.

Fig. 3 shows details in the planning of the designed roof, which has a total area of $301.76 \mathrm{~m}^{2}$, as well as the dimensions to be covered by the main structural components as beams, hip rafters and ridge broad. As shown in Fig. 3, the whole roof is supported only by four columns, which force the lateral and frontal beams to exceed spans over $18 \mathrm{~m}$ without intermediary supports.

\section{Development of Structural Design of the Beams}

As dead load on structure, besides the self-weight of structural components, it was considered a loading corresponding to tiles weight, rafters and purlins of 19.61 MPa applied directly over plate elements. The wind action was also considered as horizontal effort, calculated according to the vertical area of roof projection, with a pressure corresponding to $2.94 \mathrm{MPa}$, creating a total force of $4.24 \mathrm{kN}$. These forces were thrown into the computation model as concentrated forces in three joints of the top of the roof. Those efforts are combined for calculating the beams.

\section{Computation Modeling}

The mathematic computational model was constructed using the finite element method, with plate elements to simulate the group formed by roof tiles, common rafters, battens and purlins and bar elements to simulate trusses, beams, hip rafters, ridge broad and columns. The supported basic structure is constituted of bi-dimensional frame which supports the scissors from the roof whose combination gives the three-dimensional shape to the conjunct. In the computational model, the bars were considered articulated on both sides and the plates were discretized in order to make its nodes coincide with the scissors points which support hip rafters. Fig. 4 shows the internal forces generated on spatial frame.

The adopted consideration to the modeling was a pure elastic and isotropic behavior to the material to

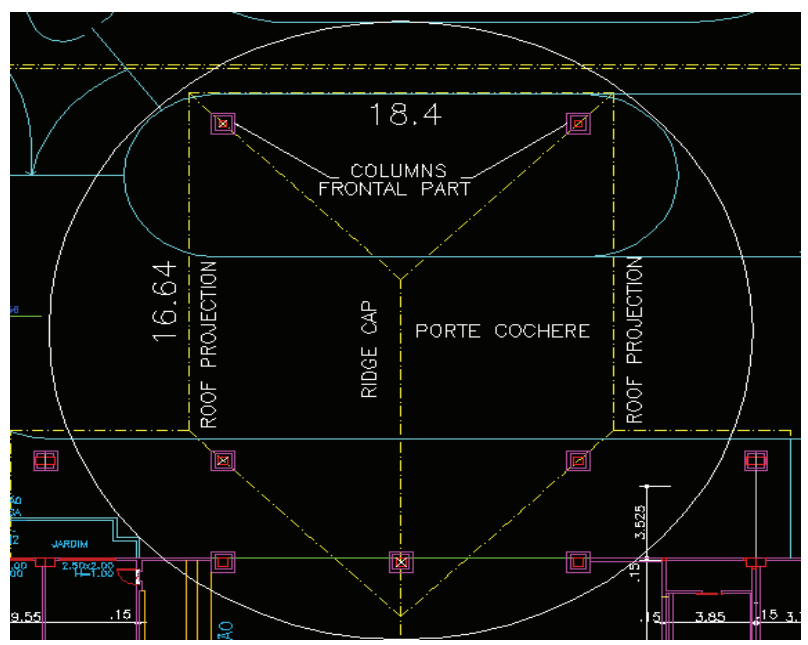

Fig. 3 Detail in plant of the structure studied.
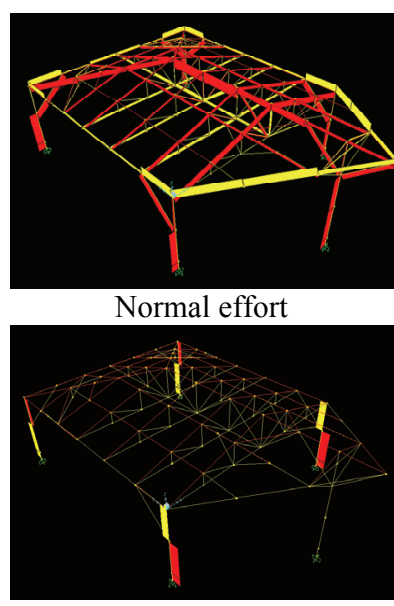

Shear effort local $(y)$

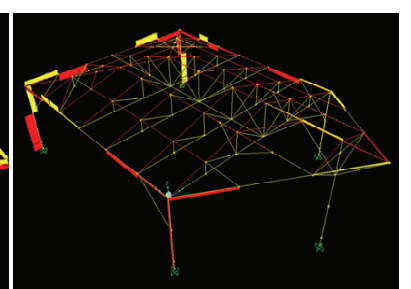

Shear effort local $(x)$

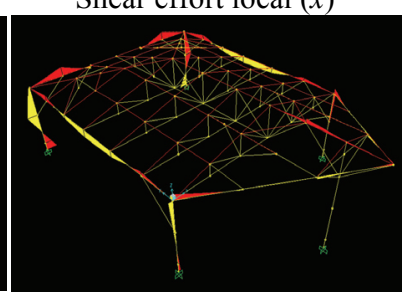

Bending moment
Fig. 4 Efforts on spatial frame. 
be an acceptable approximation for the purposes of this work. Thus it is implied that the scope of structural elements admits just linear elastic behavior and small displacement. According to Jorissen [4], timber elements are usually designed using linear elastic analysis for the calculation of both the effects of the loads in the structural members (strength demand) and the strength of member in its cross-sections (strength capacity). This is the only design method currently recommended in the Eurocode. Kima [5] registers that modeling efforts have been conducted to predict the behavior of timber structures that range from simple analytical models based on linear elastic theory to three-dimensional FEA (finite element analysis) models, even though wood is an anisotropic material.

The elastic proprieties to material introduced into the computation model are based in the following expressions, with $E_{c 0}$ considerate to $24,500 \mathrm{MPa}$, in accordance to ABNT (Brazilian Association of Technical Standards) [6], which leads to the following values, considering the changes presented in Section 5 .

$$
E_{c 0 \text { ef }}=k_{\text {mod }} E_{c 0}
$$

Then, $E_{c 0 e f}$ is the Young Modulus equals to $13,720 \mathrm{MPa}$ and the poison ratio was attributed the value 0.4 taking as reference the Wood Handbook [7].

It is interesting to mention that the option to represent the structure computationally depends on the engineer's judgment according the problem under the study, along with the preparation and processing time. Several modeling options have been used to analyze different aspects of wooden structures. In to this regard, Lee [8] relates that engineering design consists of several steps such as mathematical modeling, application of physics, theoretical and computational analysis, and incorporation of the analysis results onto the design. To some extent, the structural mechanics history is the history of simplified models development for complicated structures. Complex theory of analysis is almost impossible in real world problems. Furthermore, development of simplified models for complicated structures depends on very much the availability of an advanced analysis tool.

As stated by Schmidt [9], wood is one of the oldest materials utilized in engineering constructions. The material is used in buildings, bridges, towers, and many more structures. It is well-known due to its usage over thousands of years. Due to the need for the creation of new wood products in new areas of application, predictive methods and models for the simulation of structural behavior are required. One of these approaches is the FEM (finite element method).

In the same direction, Jenkel [10] affirms that recently, different numerical models to analyze wooden structures by means of an FE-analysis have been developed and published. These methods include material models on different scales length to simulate damage and failure as well as to capture the hygroscopic mechanical behavior.

For that reason, researchers have been in a quest for a more accurate representation of material behavior models by FEM for many years. Toson [11] researched modeling by finite element method in wooden structures of balsa under severe loadings proposing a model that could represent the complex response of balsa wood material under different types of loading.

Tarabiat [12] conducted a study for a static and dynamic three-dimensional model for the analysis of light-frame wood structures, which consists of an assembly of vertical, horizontal and diagonal diaphragms connected along their edges. Bucalem [13] can be consulted regarding hierarchical modeling using finite element solution. A modeling option similar to this paper was used by Wang and Eamon [14] to obtain theoretical reaction values.

\section{Structural Dimensioning}

The dimensioning of the beams were conducted assuming a resistance class of timber $60 \mathrm{MPa}$ and always following the recommendations of NBR 
7190 - design of timber structures, from the ABNT (Brazilian Association of Technical Standards) [6]. Efforts on the structural elements were extracted from the computational model presented in the previous section and the cross sections were calculated by observing resistance and stability guarantees, always taking into account the necessary creep influence. Wahrhaftig [15] states that creep is associated with a viscoelastic behavior of wood and its general characteristics can be influenced by intrinsic factors to the material and the environment in which it is inserted, paying special attention to the geometry and boundary conditions of the structural element. The viscoelastic behavior of the wood material to design of wooden structure is highlighted by Ormarsson [16] when formulating mathematical procedure within the principles of FEM.

The special challenges are related to the design beams, for which the cross sections found a particular solution. It is necessary to mention the fact that there is a shortage of commercial GLT (glued laminated timber) and insufficient supply of a particular type of wood to attend the roof assembly needs, causing the need for the mechanical composition of structural elements and to use different tropical species.

The dimensioning of the most required cross-section followed the criteria recommended for pieces under normal plus bending stress and for the case of long pieces the consideration of creep. Regarding the dimensioning of pieces under compression and bending, an interesting study on the design of columns under oblique bending braced laterally was presented by Song [17] who performed numerical and experimental studies on the behavior of these pieces, and confirmed the stability capacity and lateral bracing force of wood beam columns subjected to biaxial eccentric compression load. Song considered the following assumptions: The plane section remains plane after deformation; The stress-strain relationship is known and independent of the rate of loading; The lateral deflection is small compared to the column's geometry; The shear stress is uniformly distributed on the beam-column's cross sections; And the torque and torsional deformation are negligible. All these assumptions were considered for this work.

In order to take into account the uncertainties on the structure, coefficients for modification were used: $K_{\bmod 1}=0.7, K_{\bmod 2}=1$ and $K_{\bmod 3}=0.8$. The resistance to compressive and parallel tension to the fibers, which have guided the design of different structural parts, were then calculated according to the normative Eq. (1), obtaining $24 \mathrm{MPa}$ and $18.48 \mathrm{MPa}$, with $\gamma_{w c}$ and $\gamma_{w t}$ equal to 1.4 and 1.8 respectively, as the safety coefficients.

$$
f_{c 0 d}=k_{\bmod } \frac{f_{c 0 k}}{\gamma_{w c}} \text { and } f_{t 0 d}=k_{\bmod } \frac{f_{t 0 k}}{\gamma_{w t}}
$$

Due to the presence of metal bolts, the inertia of the beams was reduced taking into account a factor of reducer. That procedure favors security against plastic accommodation of the connections of wood. According to Kharouf [18], the mechanical behavior of wood connections is very complex and it is influenced by a number of geometric, material and loading parameters, so that bolt hole contact introduces high localized stress concentrations. Another concern in this direction comes from Wilkinson [19] when he analyzed the mechanical joints in wood using FEM, considering the problem with strains being nonlinear with load due to the increasing area of pin-plate contact with applied load.

In Resch's research [20], he considers that in such cases, the connections always transmit forces via surface contact between the wood components and fasteners. Therefore, a realistic formulation of the contact is of great importance for analyzing the load bearing behavior. The contact stiffness depends on different influence factors on the friction consideration between fasteners and wood components, and on approaches that taking into consideration the cylindrical geometry of the contact surface. 


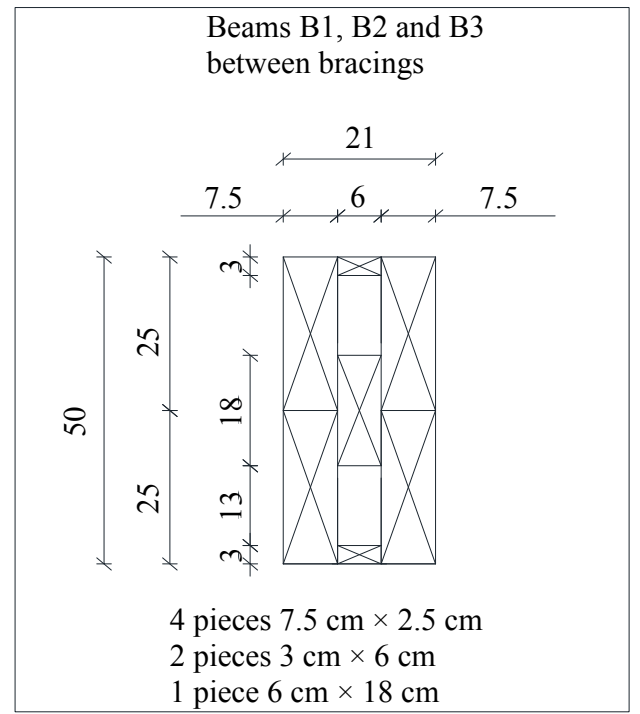

Fig. 5 Beams - section designed (unit in $\mathrm{cm}$ ).

\section{Ultimate Limit State}

The beam was idealized to be a composite section. The composition took into account the pieces as showed in Fig. 5. The geometric proprieties of the section with structural interest are:

Area:

$$
\begin{aligned}
& A=4(7.5 \mathrm{~cm} \cdot 25 \mathrm{~cm})+2(6 \mathrm{~cm} \cdot 3 \mathrm{~cm})+ \\
& (6 \mathrm{~cm} \cdot 18 \mathrm{~cm}) \Rightarrow A=894 \mathrm{~cm}^{2}
\end{aligned}
$$

Inertia about $x$ direction:

$$
\begin{aligned}
& I_{x}=4\left[\begin{array}{l}
\frac{7.5 \mathrm{~cm}(25 \mathrm{~cm})^{3}}{12}+ \\
(7.5 \mathrm{~cm} \cdot 25 \mathrm{~cm})\left(\frac{25 \mathrm{~cm}}{2}\right)^{2}
\end{array}\right]+ \\
& 2\left(\frac{6 \mathrm{~cm}(3 \mathrm{~cm})^{3}}{12}+(6 \mathrm{~cm} \cdot 3 \mathrm{~cm})\left(25 \mathrm{~cm}-\frac{3 \mathrm{~cm}}{2}\right)^{2}\right)+ \\
& \frac{6 \mathrm{~cm}(18 \mathrm{~cm})^{3}}{12} \Rightarrow I_{x}=179,074 \mathrm{~cm}^{4}
\end{aligned}
$$

Inertia about $y$ direction:

$$
\begin{aligned}
& I_{y}=4\left[\begin{array}{l}
\frac{25 \mathrm{~cm}(7.5 \mathrm{~cm})^{3}}{12}+ \\
(7.5 \mathrm{~cm} \cdot 25 \mathrm{~cm})\left(\frac{6 \mathrm{~cm}}{2}+\frac{7.5 \mathrm{~cm}}{2}\right)^{2}
\end{array}\right]+ \\
& 2\left(\frac{3 \mathrm{~cm}(6 \mathrm{~cm})^{3}}{12}\right)+\frac{18 \mathrm{~cm}(6 \mathrm{~cm})^{3}}{12} \Rightarrow I_{y}=38,199 \mathrm{~cm}^{4}
\end{aligned}
$$

Once there is a composite section, there is an inertia reducer $\left(R_{I}\right)$ in both cases equal to 0.7 .

\subsection{Verification in Flexion Compression}

The design efforts for verifying in flexion compression are:

- normal effort of compression: $N_{d}=25.321 \mathrm{kN}$;

- bending moment about $x: M_{x d}=44.589 \mathrm{kNm}$;

- bending moment about $y: M_{y d}=3.612 \mathrm{kNm}$.

The expressions recommended by NBR 7190/97 and results for verification are shown in Eqs. (3) and (4):

$$
\begin{aligned}
& \left(\frac{\sigma_{N d}}{f_{c 0 d}}\right)+\frac{\sigma_{M x d}}{f_{c 0 d}}+K_{M} \frac{\sigma_{M y d}}{f_{c 0 d}}=0.145 \\
& \left(\frac{\sigma_{N d}}{f_{c 0 d}}\right)+K_{M} \frac{\sigma_{M x d}}{f_{c 0 d}}+\frac{\sigma_{M y d}}{f_{c 0 d}}=0.096
\end{aligned}
$$

where, $K_{M}=0.5$, and

$$
\sigma_{N d}=\frac{N_{d}}{A}, \sigma_{M x d}=\frac{M_{x d}(125 \mathrm{~cm})}{I_{x}}, \sigma_{M y d}=\frac{M_{y d}(7.8 \mathrm{~cm})}{I_{y}}
$$

are the normal stresses produced by normal effort, bending moment about $x$ and bending moment about $y$.

\subsection{Verification in Relation to Stability}

The verification in relation to stability took into account a length of buckling $L_{b}=10.09 \mathrm{~m}$ (between bracings). For that reason, the slander about $x$ and $y$ are:

$$
i_{x}=\sqrt{\frac{I_{x} R_{I}}{A}}=11.8 \mathrm{~cm}, \lambda_{x}=\frac{L_{b}}{i_{x}} \Rightarrow \lambda_{x}=85.21
$$

and

$$
i_{y}=\sqrt{\frac{I_{y} R_{I}}{A}}=5.463 \mathrm{~cm}, \lambda_{x}=\frac{L_{b}}{i_{x}} \Rightarrow \lambda_{x}=184.69
$$

The evaluation of the stability is done taking into account the action of both moments in the follow terms:

$$
\frac{\sigma_{M x d}}{f_{c 0 d}}+\frac{\sigma_{M y d}}{f_{c 0 d}} \leq 1
$$

with $\sigma_{M x d}$ and $\sigma_{M y d}$ as in Eqs. (3) and (4), but, in 
this case, the bending moments, for $x$ and $y$ direction, just changing the sub index, should be calculated by Eq. (6):

$$
\begin{aligned}
& M_{x d}=N_{c d} e_{d x}, N_{c d}=N_{c k} \gamma, \\
& e_{d x}=e_{l e f x}\left(\frac{F_{E x}}{F_{E x}-N_{c d}}\right), F_{E x}=\frac{\pi^{2} E_{c 0 e f} I_{x}}{L_{b}^{2}}, \\
& e_{l e f x}=e_{i x}+e_{a x}+e_{c x}, \quad e_{i x}=\frac{M_{x k}}{N_{c k}}, \\
& e_{c x}=\left(e_{i g x}+e_{a x}\right) \exp \left(\frac{\phi\left[N_{g k}+\left(\psi_{1}+\psi_{2}\right) N_{q k}\right]}{F_{E x}-\left[N_{g k}+\left(\left(\psi_{1}+\psi_{2}\right) N_{q k}\right)\right]}\right)
\end{aligned}
$$

Adopting $\phi=0.8, \psi_{1}=0.6, \psi_{2}=0.4$ and $\gamma=1.4$; $e_{c x}=1.10 \mathrm{~cm}, e_{d x}=182.50 \mathrm{~cm}, e_{c y}=0.53 \mathrm{~cm}$ and $e_{d y}=19.11 \mathrm{~cm}$ are found. So that the condition for verification established by Eq. (5) is 0.176 .

\subsection{Verification in Relation to Shearing}

The design shear effort is $V_{d}=39.29 \mathrm{kN}$ and the static moment about the centroid is

$$
\begin{aligned}
& Q=7 \mathrm{~cm} \cdot 25 \mathrm{~cm} \cdot 12.5 \mathrm{~cm}+ \\
& 6 \mathrm{~cm} \cdot 3 \mathrm{~cm}(12.5 \mathrm{~cm}-3 \mathrm{~cm}) \\
& +9 \mathrm{~cm} \cdot 6 \mathrm{~cm} \cdot 9 \mathrm{~cm}=2,826.50 \mathrm{~cm}^{3}
\end{aligned}
$$

The shear stress, using the general expression from mechanic of solids, is:

$$
\begin{aligned}
& \tau=\frac{V_{d} Q}{b I_{x}}, \text { with } b=7.5 \mathrm{~cm} \cdot 2+6 \mathrm{~cm} \\
& \Rightarrow \tau=0.295 \mathrm{MPa}
\end{aligned}
$$

The resistance against the shearing is $5.6 \mathrm{MPa}$, given by division of $8.0 \mathrm{MPa}$ per 1.4.

\section{Serviceability Limit States}

The maximum displacement found by FEM model was $3.29 \mathrm{~cm}$, as showed in Fig. 6. The value permitted for standard condition is $\delta_{\text {adm }}=L_{b} / 300=$ $3.36 \mathrm{~cm}$. So the section designed has been completely verified by using the most severe conditions as for ULS and SLS.

\section{Some Comments about Executive Aspect}

After dimensioned, the pieces were drawn and detailed, creating the final drawing, and then sent to the implementation site of the structure. Initially planned as box beams of composite section, as defined in Fig. 5, they were executed with a very different section from the designed section, being necessary to strengthen these elements at the time of their execution due to the risk of lateral buckling, in view to the fact that the relationship between height $(h)$ and width $(b)$ exceeds 5 times, as can be observed well in Fig. 7. The reinforcement of this important structural component was performed by adding lateral pieces to approximate the shape of the beam section to the type "I", ribbed laterally arranged aimed at preventing buckling of the web. The upper and lower parts as well as the ribs have been attached to the existing elements by means of nails arranged along the height, being the ribs spaced a each $30 \mathrm{~cm}$ at the longitudinal direction of the beam. Fig. 8 shows how the reinforcement of the lateral and frontal sections of the beams was executed.

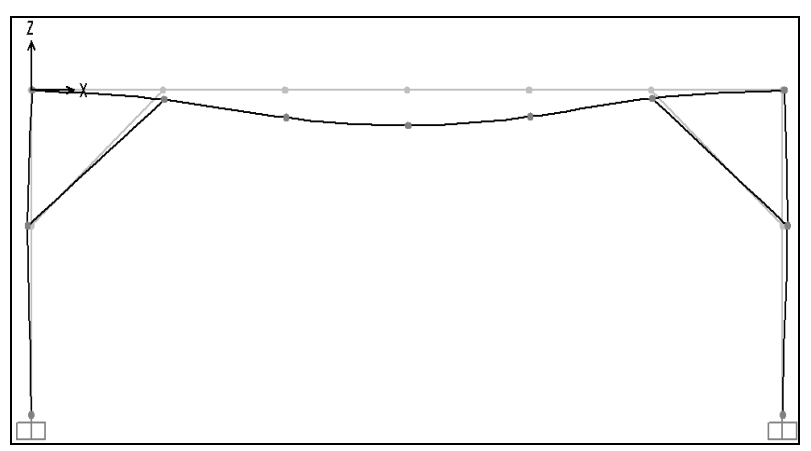

Fig. 6 Maximum displacement found $-3.29 \mathrm{~cm}$.

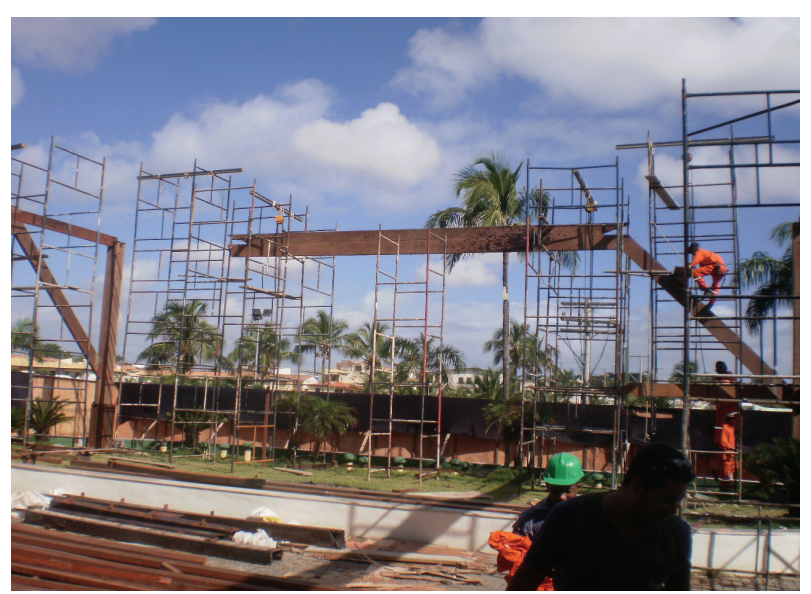

Fig. 7 Lateral beam, section executed $10 \times 55 \mathrm{~cm}^{2}$. 


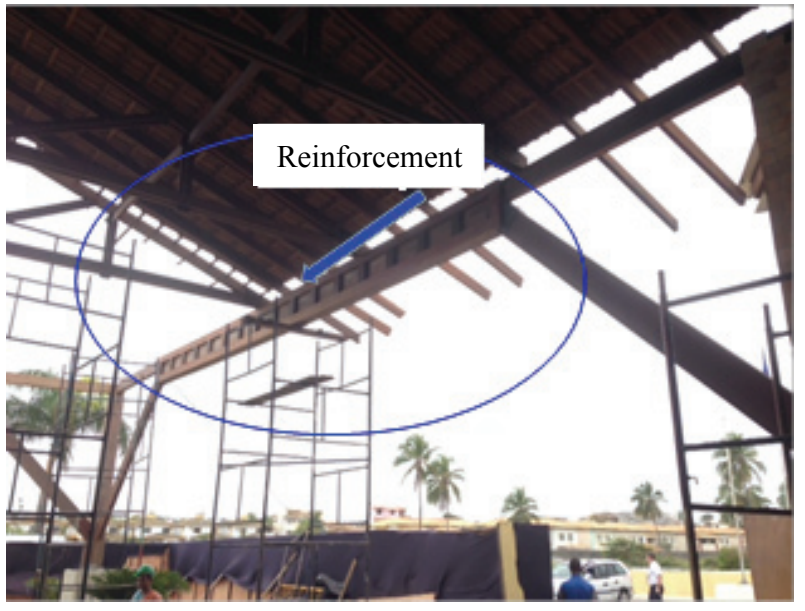

Fig. 8 Reinforced section of the beams.

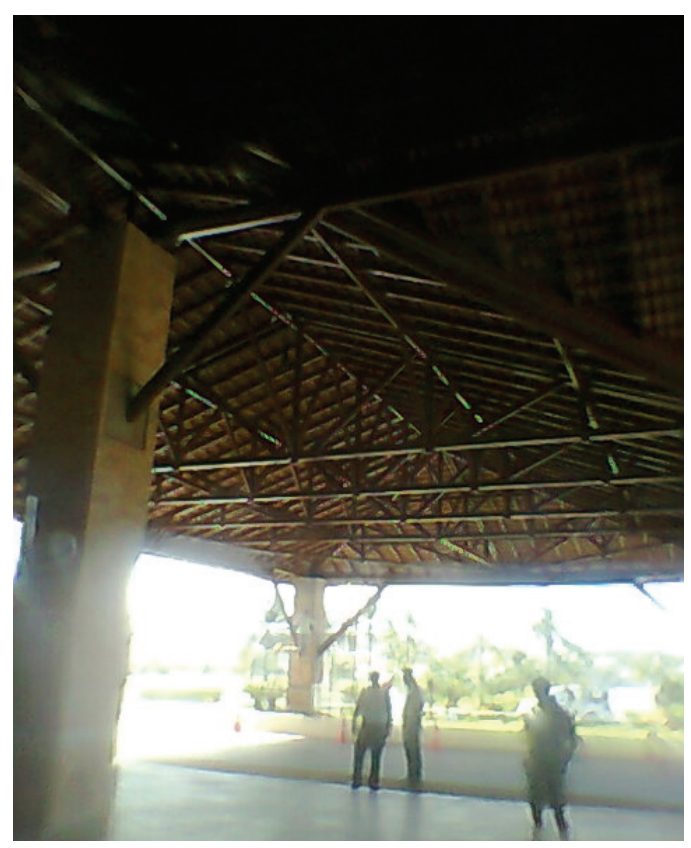

Fig. 9 View of the roof after execution.

Fig. 9 shows a bottom to top view of the roof after the final execution.

\section{Conclusions}

As a result of this work, we conclude that two important records are worthy to be made: The first is the fact that, in aggressive environments, wooden structures are more advantageous than the steel structures considering the required maintenance; Second is that the computational geometric modeling of the structure was crucial to find the complex solutions demanded by the project, as well as that the numerical modeling allowed the design of evaluation efforts, and the study of possible solutions.

A third notable aspect is the difficulty presented by the carpenters to read the detailing plans, which has led the structure to be performed with a series of local improvisations with solutions adopted on the execution site, based on empirical experience accumulated by the workers, which could compromise the final behavior of the structure. Therefore, it is evident the need to invest in the training of professionals in carpentry, both for now and future generations. Another item related to this aspect is the need to establish a channel of effective communication between designers and execution personnel, to be able to reduce the mounting difficulties to implement the solutions indicated in the plans and technical drawings of the structural design.

In closing, it is important to accentuate that the design of a wood structure requires knowledge and creativity to overcome the rising challenges and typical needs for this particular material.

\section{References}

[1] Vilasboas, J. M. L. 2003. "Durability of Buildings of Reinforced Concrete in Salvador: A Contribution to the Implementation of NBR 6118: 2003." Master thesis, UFBA (Universidade Federal da Bahia). (in Portuguese)

[2] Portella, M. O. G., Portella, K. F., Pereira, P. A. M., Inone, P. C., Brambilla, K. J. C., and Cabussú, M. S., et al. 2012. "Atmospheric Corrosion Rates of Copper, Galvanized Steel, Carbon Steel and Aluminum in the Metropolitan Region of Salvador, Ba, Northeast Brazil." In Proceedings of 20th International Congress of Chemical and Process Engineering, 171-85.

[3] Bijen, J. 2003. Durability of Engineering Structures: Design, Repair and Maintenance. Amsterdam: Elsevier.

[4] Hansson, E. F. 2011. "Analysis of Structural Failures in Timber Structures: Typical Causes for Failure and Failure Modes." Engineering Structures 33 (2011): 2978-82. doi:10.1016/j.engstruct.2011.02.045.

[5] Jorissen, A., and Fragiacomo, M. 2011. "General Notes on Ductility in Timber Structures." Engineering $\begin{array}{lll}\text { Structures } & 33 & \text { (2011): }\end{array}$ doi:10.1016/j.engstruct.2011.07.024.

[6] Kima, Y. J., and Harries, K. A. 2010. "Modeling of Timber Beams Strengthened with Various CFRP 
Composites." Engineering Structures 32 (2010): 3225-3234, doi:10.1016/j.engstruct.2010.06.011.

[7] ABNT (Brazilian Association of Technical Standards). 1997. NBR 7190-Design of Wooden Structures. Rio de Janeiro: ABNT. (in Portuguese)

[8] Wood Handbook. 2010. Wood as an Engineering Material. United States Department of Agriculture, Forest Service, Forest Products Laboratory general technical report, FPL-GTR-190, Madison, Wisconsin.

[9] Lee, K. W., Chong, T. H., and Park, G. J. 2003. "Development of a Methodology for a Simplified Finite Element Model and Optimum Design." Computers and $\begin{array}{llll}\text { Structures } & 81 & \text { (2003): } & 1449-60 .\end{array}$ doi:10.1016/S0045-7949(03)00084-1.

[10] Schmidt, J., and Kaliske, M. 2009. "Models for Numerical Failure Analysis of Wooden Structures." Engineering Structures $31 \quad$ (2009): $571-9$. doi:10.1016/j.engstruct.2008.11.001.

[11] Jenkel, C., and Kaliske, M. 2014. "Finite Element Analysis of Timber Containing Branches: An Approach to Model the Grain Course and the Influence on the Structural Behavior." Engineering Structures 75 (2014): 237-47. doi:10.1016/j.engstruct.2014.06.005.

[12] Toson, B., Viot, P., and Pesqué, J. J. 2014. "Finite Element Modeling of Balsa Wood Structures under Severe Loadings." Engineering Structures 70 (2014): 36-52. doi:10.1016/j.engstruct.2014.03.017.

[13] Tarabiate, A. M. and Itanig, R. Y. 1997. "Static and Dynamic Modeling of Light-Frame Wood Buildings." Computers and Structures 63 (2): 319-34. doi:10.1016/S0045-7949(96)00344-6.

[14] Bucalem, M. L., and Bathe, K. J. 2011. The Mechanics of Solids and Structures-Hierarchical Modeling and the
Finite Element Solution. Berlin: Springer.

[15] Wang, W., and Eamon, C. D. 2013. "Load Path Uncertainty in a Wood Structure and the Effect on Structural Reliability.” Engineering Structures 56 (2013): 889-96. doi:10.1016/j.engstruct.2013.06.006.

[16] Wahrhaftig, A. M., César, S. F., and Oliveira, E. N. 2012. Initial Considerations of Creep in Compressed Pieces of Wood. Bahia: Polytechnic Institute of Bahia. (in Portuguese)

[17] Ormarsson, S., and Dahlblom, O. 2013. "Finite Element Modelling of Moisture Related and Visco-Elastic Deformations in Inhomogeneous Timber Beams." Engineering Structures $49 \quad$ (2013): $182-9$. doi:10.1016/j.engstruct.2012.10.019.

[18] Song, X., and Lam, F. 2009. "Laterally Braced Wood Beam-Columns Subjected to Biaxial Eccentric Loading." Computers and Structures 87 (2009): 1058-66. doi:10.1016/j.compstruc.2009.04.007.

[19] Kharouf, N., McClure, G., and Smith I. 2003. "Elasto-Plastic Modeling of Wood Bolted Connections." Computers and Structures 81 (2003): 747-54. doi:10.1016/S0045-7949(02)00482-0.

[20] Wilkinson, T. L, Rowland, R. E., and Cooks, R. D. 1981. "An Incremental Finite-Element Determination of Stresses around Loaded Holes in Wood Plates." Computers and Structures 14 (I-2): 123-8. doi:10.1016/0045-7949(81)90091-2.

[21] Resch, E., and Kaliske, M. 2010. "Three-Dimensional Numerical Analyses of Load-Bearing Behavior and Failure of Multiple Double-Shear Dowel-Type Connections in Timber Engineering." Computers and $\begin{array}{llll}\text { Structures } & 88 & \text { (2010): } & \text { 165-77. }\end{array}$ doi:10.1016/j.compstruc.2009.09.002. 